\title{
Thomas Hobbes como historiador: a Ciência civil na historiografia
}

\section{Thomas Hobbes as a historian: civil science in historiography}

\author{
Debora Regina Vogt \\ vogt.deboraregina@gmail.com \\ Doutoranda \\ Universidade Federal do Rio Grande do Sul \\ Av. Mal Juarez Tavora, 400, 82B \\ 05750-000 - São Paulo - São Paulo \\ Brasil
}

\section{Resumo}

Este estudo procura compreender, em linhas gerais, o sentido da história para Thomas Hobbes. Embora ele seja principalmente um pensador preocupado com sua Ciência civil, ele também fez da história objeto de estudo e análise, chegando a escrever uma obra sobre a Revolução Inglesa. Partindo tanto do entendimento da história como mestra da vida como o sentido do passado para o filósofo, por meio da reflexão sobre seus contatos com a narrativa histórica, procura-se demonstrar o sentido que a historiografia teve para um autor que não se via como historiador, embora tenha feito dela veículo de atuação política. Procura-se demonstrar o sentido que a história como magistra vitae adquiriu em seu contexto e de que forma ela relaciona-se com a concepção de natureza humana que transparece no pensamento maior de Hobbes. Entre a história como ensino e como saída para o estado de natureza é conduzido esse trabalho.

10 Palavras-chave

História das ideias; Thomas Hobbes; Historia magistra vitae.

\begin{abstract}
This study searches a general understanding on Thomas Hobbes' sense of history. Although mainly concerned with his Civil Science, Hobbes also made of history an object of study and analysis, writing a book on the English Revolution. Starting from the understanding of history as a teacher of life and of the philosopher's sense of the past, by means of reflections on their contacts with the historical narrative, this study seeks to demonstrate the sense of historiography of an author that did not see himself as historian, although having made of it a way of political action. It seeks to demonstrate the sense that history - as magistra vitae - has taken in the context of his oeuvre and its relationship with the notion of human nature that emerges of Hobbes' quintessential thinking. This work is conducted between history as a teaching matter and as a solution to the state of nature.
\end{abstract}

\section{Keywords}

History of Ideas; Thomas Hobbes; Historia magistra vitae. 
[...] mas a própria construção repousa nos fatos e nas palavras: a inteligência dos fatos requer a ordem dos tempos e a descrição dos lugares. Pede também, já que em fatos importantes e dignos de memória [...] sobre os feitos, que se declare não só o que se fez ou se disse, mas também de que modo [...] e não se fale só dos feitos dos próprios homens, mas, com relações aos que se distinguem pela reputação e pelo nome, também da vida e do caráter de cada um [...] (Cícero, Do Orador, II, grifos meus).

Thomas Hobbes, assim como Nicolau Maquiavel, Galileu Galilei, JeanJacques Rousseau, Francis Bacon, entre outros, é colocado como um dos grandes nomes da modernidade ocidental. Conhecido por suas teorias a respeito do poder soberano e da natureza humana, o pensador é presença constante em livros didáticos e em disciplinas de Filosofia, Ciência Política e História. Ele está em nosso Panteon acadêmico e é arrolado como um dos grandes pensadores e idealizadores do Estado moderno, pré-configuração do que será, posteriormente, o Estado como nós conhecemos hoje. Entender suas obras é compreender mais do que um autor importante, mas apreender conceitos fundamentais para a construção do Estado moderno e do nosso mundo atual.

O objetivo desse artigo é refletir sobre a prática historiográfica de Hobbes, que não se via como historiador, mas que tinha a narrativa como veículo de demonstração da Ciência civil, necessária à vida em sociedade. Para isso, é apresentada a Ciência civil hobbesiana como veículo maior de seu pensamento, na qual a narrativa histórica se insere, compreendendo a história como uso da narrativa para demonstrar, para outros públicos, a necessidade de sua Ciência civil.Como presença constante em manuais de filosofia e de ciência política, estudiosos de Hobbes criaram definições didáticas com o objetivo de facilitar a apreensão de um autor múltiplo como é o filósofo. Assim, ao se estudar o pensador, alguns pressupostos são afirmados como "dados", "prontos", através dos quais se pensa e se analisa seus textos. Fruto da modernidade e da crença que essa traz em relação à razão, juntamente com seu uso do método hipotético dedutivo, Hobbes se colocaria como um dos rompedores da tradição medieval, muito inspirada em Aristóteles, que até então marcava as universidades. Seu desejo era criar uma ciência da moral e da política, já que, segundo ele, as opiniões são variáveis como diferentes são os homens. Sua construção de uma ciência moral estaria pautada no modelo da ciência natural. Desta forma, os modelos de Hobbes são laicos e diferem dos aristotélicos em sua essência, já que não pressupõem o homem como animal político.

Entretanto, se Hobbes via a si mesmo como alguém que estava longe de vários de seus contemporâneos, admiradores das teorias de Aristóteles, vários desses elementos que ele contestou e discordou são a base conceitual através do qual pensou, leu e escreveu. Ou seja, mesmo que o filósofo seja arrolado por nós no quadro dos "modernos" em nossos livros didáticos e aulas, as definições são limitadas em relação a possibilidades de explicação de um autor múltiplo como é Hobbes. O pensador era um moderno, mas também era um humanista, era um seguidor e admirador das novidades trazidas pelos 
novos conhecimentos científicos, mas também era um admirador de Tucídides e de outros escritores antigos. Escreveu textos sobre geometria, sobre filosofia, sobre as ciências naturais, procurou criar uma ciência moral e também escreveu história, como faziam os humanistas em sua época. Embora, por recursos didáticos, tenhamos por costume "encaixotar" pensadores em definições de modo a facilitar a compreensão, quando observados atentamente, fogem de nossas pré-definições.

Além dos tratados políticos que marcam seu pensamento e tornaram Hobbes conhecido mesmo após sua época, o autor escreve sobre ciência, matemática e história. Segundo Bruno Latour, inclusive, enquanto Robert Boyle teria criado o discurso científico moderno, Thomas Hobbes inauguraria o discurso político, baseado em elementos que conhecemos hoje: representação, contrato, propriedade e cidadãos. ${ }^{1}$

Hobbes é, dessa forma, um dos nomes que marca a modernidade. Conhecido principalmente por sua obra, Leviatã, ele estabelece muitas das bases que formam o Estado Político Moderno. Ele é referência no que se refere à definição de poder absoluto e a quebra de conceitos que a modernidade trouxe. No entanto, além de demonstrar como funciona a natureza humana e a necessidade de um poder soberano capaz de controlar a força irremediável que levava os homens ao estado de natureza, o pensador decide contar aos seus contemporâneos uma história que viveu: a guerra civil inglesa.

Behemoth ou o Longo Parlamento, obra narrativa do pensador, foi escrito 12 no final da vida de Hobbes, em 1668, tendo publicação oficial somente após a morte do autor. Hobbes queria vê-lo publicado, mas, ao pedir autorização a Carlos II, seu ex-aluno, ela foi negada. No entanto, várias cópias circulavam na Inglaterra, mesmo sem o consentimento do autor (TÖNNIES 2001, p. 25- 29). A primeira edição só sairia três anos após a morte do filósofo, por seu amigo e editor William Crooke. Foram quatro os manuscritos deixados pelo filósofo, mas só um recebeu revisão, o de Ferdinand Tönnie, publicado em 1889 e traduzido para o português em 2001 por Eunice Ostrensky.

Nesta obra, Hobbes, curiosamente, mas não sem razão, utiliza-se de uma metáfora bíblica. A contraposição ao Leviatã é evidente e embora na Bíblia não haja uma clara valorização dele ${ }^{2}$ em relação ao Behemoth, o filósofo desejava demonstrar aos seus contemporâneos as duas situações em que a sociedade poderia se encontrar. A linguagem bíblica é, neste caso, um vocabulário comum, compartilhado pelos leitores de seu discurso. Mesmo que Hobbes atacasse com veemência e de modo explícito aqueles que se utilizam da palavra como engano,

\footnotetext{
1 "A escolha de tratar ao mesmo tempo de Hobbes e Boyle tern algo de genial, uma vez que o novo principio de simetria, destinado a explicar ao mesmo tempo a natureza e a sociedade (ver abaixo) nos e imposto pela primeira vez nos estudos sobre a ciência através de duas grandes figuras do inicio da era moderna. Hobbes e seus seguidores criaram os principais recursos de que dispomos para falar do poder - representação, soberano, contrato, propriedade, cidadãos -, enquanto que Boyle e seus seguidares elaboraram urn dos repertórios mais importantes para falar da natureza - experiência, fato, testemunho, colegas. O que nos ainda não sabíamos, e que se tratava de uma dupla invenção" (LATOUR, 1994, p. 30).

2 Ver Jó 40: 15-24. O Leviatã e o Behemoth aparecem na Bíblia nos capítulos 40 e 41 do livro de Jó. Enquanto o Leviatã é uma espécie de crocodilo ou dragão, representando um monstro marinho, Behemoth, o hipopótamo imperturbável, é um monstro terrestre.
} 
para levar o povo a se indispor com seu soberano, o pensador usou os mesmos elementos que seus opositores para convencer e persuadir: palavras e jogos de linguagem. Além do próprio título, o livro, assim como outros, é cheio de referências bíblicas.

Escrito sob a forma de diálogo, onde os capítulos são divididos como intervalos de uma conversa mais longa entre duas pessoas, as opiniões dos personagens não são distintas. Diferente de um diálogo platônico, onde as opiniões dos personagens são diferentes e há uma descrição dos que participam do diálogo, no caso do filósofo inglês, não há descrição dos interlocutores. O que é possível afirmar é que um deles, identificado como " $\mathrm{A}$ ", presenciou a guerra e a relata, enquanto o segundo, "B", ouve e faz considerações. O teor da conversa é de um relato que abarca o início da guerra, com as causas dessa e termina com a restauração do poder ao seu devido lugar, na visão de Hobbes: aos Stuart. Segundo o próprio autor, o primeiro diálogo trata-se de sementes da rebelião, ${ }^{3}$ "certas opiniões a respeito da teologia e política" (HOBBES, Behemoth, Dedicatória, p. 23), já o segundo trata-se do desenvolvimento da guerra, com documentos $^{4}$ que o Parlamento e o rei trocaram durante o conflito. O terceiro e quarto capítulo de forma muito mais enxuta e menos analítica em relação aos outros dois, tratam de uma descrição da guerra com poucas reflexões.

Assim, no Diálogo I, Hobbes afirma, pela fala de " $B$ ", quais seriam os objetivos de seu relato, após um breve período em que ambos conversavam sobre as virtudes e o uso que o clero fazia da doutrina de Aristóteles. Em determinado momento, " $A$ " questiona se eles não haviam se afastado de seu propósito, "B" responde que não, já que, para o filósofo, não bastava descrever a guerra, mas entender por que ela ocorreu, descortinar suas causas, para que se pudesse aprender com o ocorrido.

Julgo que de modo algum vos desviastes, pois suponho que vosso propósito fosse inteirar-me da história, não tanto das ações ocorridas no tempo das últimas perturbações, como de suas causas, e dos concílios e artifícios que as produziram. Há vários homens que escreveram a história, com os quais poderia aprender o que se fez, e também algo do que foi tramado, mas neles pouco encontro do que desejava perguntar. Portanto, uma vez que foi do vosso agrado o meu pedido de travar este diálogo, que agrade também a vós me informar segundo meu próprio método; e, quanto ao risco de fazer confusão que possa resultar disso, cuidarei de vos trazer de volta ao lugar onde vos retirei, visto que bem me lembro onde ficava (HOBBBES Behemoth, Diálogo I, grifos meus).

Hobbes escreve este livro com oitenta anos, após a Restauração. O filósofo olha para aqueles tempos com certa melancolia, de quem procura entender o

\footnotetext{
${ }^{3}$ É importante colocar que a revolução inglesa só foi chamada por esse nome após a Revolução Francesa, anteriormente ela era simplesmente chamada de "grande rebelião" Segundo Eunice Ostrensky, o primeiro a designar a guerra civil como revolução foi o historiador François Guizot, provavelmente como alusão à Revolução Francesa (OSTRENSKY 2006, p. 24).

${ }^{4}$ Os dois primeiros diálogos embora não tratem da guerra "em si", são para Hobbes partes dela, já que, para o filósofo, a luta não é somente o combate, mas quando os homens estão dispostos a isso: "[...] Pois a guerra não consiste apenas na batalha, ou no ato de lutar, mas naquele lapso de tempo durante o qual a vontade de travar a batalha é suficientemente conhecida [...]" (HOBBES Leviatã, Cap. XIII, p. 109).
} 
que passou, dar-Ihe um sentido, mesmo que posteriormente. Se ler o humano é essencial para quem governa, entender os atos e compreender suas atitudes é um ponto fundamental. Se as paixões humanas são as mesmas, ${ }^{5}$ como o filósofo afirma no Leviatã, os atos passados podem nos decifrar a natureza humana. Hobbes inicia desta forma seu relato:

Se no tempo, como no espaço, houvesse graus de alto e baixo, acredito firmemente que o mais alto dos tempos seria o que transcorreu entre os anos de 1640 e 1660. Pois quem do topo, como da Montanha do Diabo, olhasse o mundo e observasse as ações dos homens, sobretudo na Inglaterra, descortinaria um panorama de todas as espécies de injustiça e de loucura que o mundo pôde proporcionar, e como foram geradas pela hipocrisia e presunção- aquela dobrada iniqüidade, esta, dupla loucura (HOBBES Behemoth, Diálogo I, grifos meus).

Hobbes inicia seu relato evocando uma imagem bíblica. Se a metáfora do título parece sugestiva e evidencia alguns dos propósitos do pensador, levar seus leitores ao pináculo do templo, onde o Diabo leva Jesus para que ele se renda as riquezas e aos prazeres do mundo, evoca o caráter maligno e enganador daquela guerra. Lá, da "Montanha do diabo", é possível enxergar o que fazem os homens na terra e observar as motivações que engendraram aqueles dias. Injustiça e loucura se fizeram presentes e ações que, em tempos de paz, não se efetivariam, já que, em guerra intestina, já não há noção de certo e errado, pois não há nenhuma lei constituída e nem juiz para afirmar o que é ou não bom. Quando o Diabo leva Jesus ao Pináculo do Templo ${ }^{6}$ ele pode vislumbrar mais claramente as riquezas e prazeres do mundo. O tentador Ihe oferece tudo, já que tudo que havia sido entregue, apenas havia um pedido, que ele Ihe adorasse. Jesus recusa a oferta e o Diabo retira-se. A passagem bíblica, parafraseada por Hobbes, lembra o lugar do engano, da ilusão, para aqueles cujo vocabulário comum era o religioso.

Assim como outros humanistas, para Hobbes, a história não tem o tom de anais ou de relato emoldural. Ela nos apresenta o caráter natural humano, suas paixões e caminhos traçados. Se for possível ler o humano e, através disso, adquirir prudência, o caminho da história parece ser perfeitamente aceitável. Além disso, a que Hobbes propõe-se a narrar é peculiar e demonstra, segundo sua visão, o que é a natureza humana escondida ou velada dentro de nós. Se entendermos que, para o filósofo, a guerra civil é a volta ao estado de natureza, quando se perde os referenciais construídos quando vivemos na sociedade, fica claro que aprender sobre ela é demonstrar onde nossos atos de rebelião podem nos levar. Nas palavras de Ahrensdorf (2000): "Hobbes afirma que o

\footnotetext{
5 "[...] Pretendia ensinar-nos que, a partir da semelhança entre os pensamentos e paixões dos diferentes homens, quem quer que olhe para dentro de si mesmo, e examine o que faz quando pensa, opina, raciocina, espera, receia, etc., e por que motivos o faz, poderá por esse meio ler e conhecer todos os pensamentos e paixões de todos os outros homens, em circunstâncias idênticas. Refiro-me às semelhanças das paixões que são as mesmas em todos os homens, desejo, medo, esperança, etc., e não à semelhança dos objetos das paixões que são as coisas desejadas, temidas, esperadas, etc [...] (HOBBES, Leviatã, Introdução, grifos no original). 6 "[...] Levou- o Diabo a um monte muito alto, mostrou-lhe todos os reinos do mundo e a glória deles e Ihe disse: - Tudo te darei se, prostrado, me adorares. Então, Jesus respondeu: - Retira-te Satanás, porque está escrito ao Senhor teu Deus adorarás, e só a ele darás culto [...]" (Mateus 4, 7-10).
} 
inevitável ciclo da guerra e paz, vaidade e medo, pode ser superado através da instrução, durante o período da paz, sobre a cansativa e sanguenta experiência da guerra". Ou seja, através do aprendizado sobre a situação de conflito, poderse-ia valorizar a segurança e a paz, visando permanecer assim.

Contudo, para o pensador, essa solução ainda ocorre no plano do contingente e não de uma teoria elaborada. O fim do problema iminente da volta ao estado de natureza só se daria pelo ensino da ciência civil, entretanto, a história é exemplo e como tal deve ser lida. O problema, no entanto, é que o homem rapidamente se esquece do que viveu e ouviu, voltando frequentemente ao fluxo incontrolável de suas paixões, por isso se faz necessário a lembrança constante, para que não se esqueça do perigo que correm.

Assim, se, por um lado, existe uma filiação de Hobbes à leitura humanista da História que a concebe como instrução, por outro lado, é importante lembrar que para o filósofo a história só tem sentido dentro de um entendimento universal do ser humano, ou seja, ela é ilustração para a ciência civil, essa sim, imutável e invariável. Ela, tal como em Cícero, viria associada à eloquência e estaria ligada à divulgação da verdade para um público leigo que provavelmente não leria seus textos teóricos. Além disso, da mesma forma que a história clássica ensina, a Bíblia, quando lida da forma apropriada, traria narrativas que poderiam ensinar o presente da Inglaterra.

É como se os tempos de paz fossem necessariamente intercalados por momentos de guerra. A trajetória humana está, para o pensador, continuamente envolvida neste ciclo, entretanto, para ele, a própria história parece ser também o instrumento usado para a quebra desse ciclo inevitável da natureza (AHRENSDORF 2000). Por meio da instrução, do aprendizado sobre a guerra, seria possível, durante certo tempo, romper o ciclo, já que alertaria o homem do inevitável perigo que corre. Em tempos de paz é possível esquecer o que ocorre em momentos de guerra. Sem o conhecimento sobre a situação de caos instalada, o homem se rende a uma de suas principais paixões, a busca de louvor e honra, e esquece-se do perigo iminente.

Se não necessariamente a história torna os homens mais sábios, já que continuamente erros são repetidos, o pensador apresenta a ciência civil como caminho para a manutenção da paz. A geometria seria o modelo e o método não só para as Ciências Naturais, mas também para a ciência civil.

Semelhante a um ciclo que, neste caso, não necessariamente volta ao mesmo lugar, mas que repete certas formas estruturais, já que as paixões humanas, em diferentes tempos, são as mesmas, a guerra civil deve ser entendida como uma eterna possibilidade, latente na natureza humana. Semelhante ao movimento dos astros no espaço, pensado no século XVII, em que o sentido de revolução é mover em giro, as mudanças humanas fazem parte de um ciclo maior, que rege tanto a natureza como a sociedade. Embora o ideal seja que se estabeleça um governo de paz e não de conturbações, não é possível enganar-se: sempre existe a possibilidade de tais como nos ciclos naturais, o estado de natureza voltar. No final do quarto diálogo do Behemoth, por exemplo, Hobbes afirma: 
Vi nesta revolução um movimento circular do poder soberano, que foi do falecido rei para seu filho, passando por dois usurpadores, pai e filho. Pois (deixando de lado o poder do conselho de oficiais, que foi temporário e cujos detentores se consideravam apenas procuradores) moveu-se do rei Carlos I para o Longo Parlamento; daí para o Rabo; do Rabo para Oliver Cromwell; e então para de volta de Richard Cromwell para o Longo Parlamento; deste, para o rei Carlos II, onde se espera que permaneça por muito tempo (HOBBES, Behemoth, Diálogo IV, grifos meus).

Quando Hobbes coloca a história num sentido cíclico, insere-se dentro de uma nova visão de história, ${ }^{7}$ que, rompendo com as heranças de um tempo escatológico cristão, que colocava tudo em direção ao fim do mundo, retoma, de certo modo, uma visão antiga de tempo cíclico. Assim como são cíclicos os eventos da natureza, seriam também as formas de governo. Sendo a história temporalmente cíclica, é possível prever o futuro baseando-se nas experiências do passado. Sendo o futuro matematicamente calculável, é possível estabelecer um prognóstico dele, embora esse possa ser, de certo modo, profético, devido ao caráter permanente da natureza humana. Olha-se para o passado, que no caso é a Antiguidade Clássica, e se prevê o futuro, ou, nas palavras de Reinhard Kosselleck (2006, p. 36), "coloca-se o passado no futuro".

Entre o passado e o presente de sua escrita o pensador dá entendimento não só ao que narra, mas reitera o que apresenta como sendo a natureza humana que permite entender todos os homens. O medo da guerra civil é uma constante, já que os laços da vida social são frágeis, principalmente devido às paixões humanas. Assim, entre o passado e o presente, Hobbes apresenta a sua narrativa, procurando reiterar entendimentos sobre a natureza humana e a necessidade da obediência ao soberano. Se pudermos aprender com o passado, evitaremos o mal que a guerra civil traz sobre a vida em sociedade e a paz será mantida.

\section{Passado e presente como conceitos históricos}

Passado e presente são conceitos assimétricos que andam juntos na reflexão teórica e narrativa histórica. Quando um dos conceitos é mencionado, o outro está subentendido, já que não há como ter passado sem presente. São os conceitos assimétricos, citados por Reinhart Koselleck (2006), que ao mesmo tempo em que são contrapostos, caminham juntos no entendimento, por vezes, de toda humanidade.

Obviamente a relação entre os dois não é sempre clara e unívoca, já que engloba visões teóricas e metodológicas sobre como ocorre o processo histórico. Se o passado é percebido como algo a ser superado, ele serve apenas para deleite intelectual ou entendimento do presente. No entanto, se ele é ensino, compreensão de fatos e atitudes que podem se repetir por fazerem parte da natureza humana, seu estudo é útil à vida política e não deve ser negligenciado.

\footnotetext{
7 De acordo com Koselleck (2006, p. 21-39), o tempo moderno passaria do escatológico, com as constantes profecias referentes ao fim do mundo em direção ao cíclico, numa retomada dos antigos e por fim no tempo linear, que bebe suas fontes na escatologia, ao colocar a revolução como ponto alto antes mesmo da Revolução Francesa.
} 
Os dois conceitos são fundamentais na escrita dos que têm a história como horizonte central. A partir do presente e seu lugar de fala é que se produz o entendimento sobre o passado e o que ele significa para o contexto contemporâneo. Contudo, se atualmente - após a Revolução Francesa e os questionamentos relativos à história como mestra da vida e como constante evolução - compreendemos a história como não passível de repetição, para os modernos ela era como um ciclo, repetível e possível de apreender. O estudo do passado era justificável na medida em que era possível que os acontecimentos se repetissem, dentro de conjunturas semelhantes.

Segundo Koselleck (2006, p. 210), tais pares de conceitos- passado e presente- unem experiências e expectativas políticas, já que carregam certa visão sobre o passado, sobre o presente e o próprio futuro. A antítese tem estruturas próprias que convergem na criação de um passado que é como o espelho do presente ou vice-versa. Nessa conjunção, o passado é ao mesmo tempo distante e próximo, pois se, por um lado, ele é antigo e afastado temporalmente, por outro, é repetível em sua forma estrutural.

O passado e o presente aparecem como elementos chaves na modernidade também, mesmo antes da profissionalização do historiador. Sem profissionais que se dedicavam integralmente à prática, pensadores modernos se dedicaram ao estudo e à reflexão sobre a história, seus objetivos e à própria prática da escrita. Sem as leituras e reflexões que temos hoje sobre a prática historiográfica, a maioria se deteve na narrativa e menos na reflexão teórica. Desta forma, podemos perceber a práxis e a compreensão sobre a historiográfica em seus textos e nas demonstrações que tinham sobre a forma como percebiam a passagem do tempo.

Embora em geral os pensadores sejam conhecidos por seus tratados filosóficos e epistemológicos, boa parte dos modernos não via a história como ciência separada das outras. Assim, vários se dedicaram à prática, mesmo sem aporte teórico, compreendendo que ela poderia ser escrita e compreendida, a fim de evitar erros futuros. A história como mestra é o que os une, embora saiam de concepções sobre o homem que podem ser contraditórias.

Hobbes, contratualista inglês e defensor do estado absolutista como única saída para o estado de natureza, foi um dos pensadores que fez da história objeto de reflexão e inspiração para seus trabalhos. A partir da narrativa sobre o passado, procurou mostrar para um público mais leigo a verdade de sua teoria e a necessidade de um poder soberano para que a paz fosse permanente. Sua forma de prática historiográfica é uma forma de demonstração da ciência civil, necessária à vida em sociedade. Se seus tratados de filosofia podiam ser indecifráveis para um público mais leigo, ele descreve a guerra civil e todo seu sofrimento a fim de alertar seus contemporâneos sobre as necessidades da vida em sociedade.

Para Thomas Hobbes o homem sem o poder soberano vive uma situação de ameaça constante, já que sem um poder constituído não há quem diga o que é certo ou errado ou quem é ou não o proprietário de alguma coisa. Isso ocasiona uma guerra intestina, em que cada um luta por sua própria sobrevivência. Diante desse quadro, os homens entregaram todo poder ao soberano para que 
ele trouxesse a paz, necessária à vida em comunidade. No entanto, em certos momentos, era necessário também lembrar ao homem a necessidade de se obedecer ao soberano, visando à manutenção de sua própria vida. Esse foi um dos principais propósitos das obras do pensador, principalmente em suas reflexões sobre a história.

Desta guerra de todos os homens contra todos os homens também isto é
consequência: que nada pode ser injusto. As noções de bem e de mal, de
justiça e injustiça, não poderiam aí ter lugar. Onde não há poder comum
não há lei, e onde não há lei não há injustiça. Na guerra, a força e a
fraude são as virtudes dos cardeais. A justiça e a injustiça não fazem
parte das faculdades do corpo e do espírito [...] Outra consequência da
mesma condição é que não há propriedade, nem domínio, nem distinção
entre o meu e o teu; só pertence a cada homem aquilo que ele é capaz
de conseguir, e apenas enquanto for capaz de conservá-lo [...]" (HOBBES
Leviatã, Cap. XIII).

Diante de uma situação de total desordem, em que a vida era constantemente ameaçada, os homens decidiram entregar todo poder civil e político a um soberano, este, por sua vez, deveria trazer a paz e a tranquilidade. A lei viria do próprio rei, que por sua palavra e pela força da espada, mantém a ordem necessária ao viver em comunidade, já que os homens não seriam naturalmente seres sociáveis.

Hobbes intervém em seu contexto não com armas ou cargos políticos, mas por intermédio da linguagem. Seus textos são veículos de atuação em seu contexto e têm como objetivo demonstrar a verdade sobre sua ciência civil. A leitura que proponho do pensador, portanto, pressupõe a concepção de que a linguagem também é um veículo de intervenção.

O mundo social, político e intelectual é codificado através da linguagem e é interessante perguntar-nos até que ponto algo existe fora da codificação linguística. A linguagem não é um espelho da realidade, mas diversos reflexos que ao mesmo tempo em que refletem, atingem o "real" também. Como imagens que nunca terminam, não há separação entre o mundo e a forma como o codificamos. Desta forma, compreendo a obra de Hobbes não como reflexo de um real exterior a ela, mas como veículo de intervenção política, que também é uma arma de ação.

É importante lembrar, inclusive, que nosso "fazer histórico", quando trabalhamos com fontes e vestígios do passado, é formado por códigos linguísticos, que devem ser interpretados por nós. O próprio contexto é textualizado, numa continua relação que construímos entre leituras e reflexões (LA CAPRA 1998, p. 241).

\section{A história e a Ciência civil em Thomas Hobbes}

Embora Thomas Hobbes tivesse como objetivo central apresentar a sua Ciência civil, deteve-se em escrever e estudar história, pois a compreendia como parte importante no estudo da natureza humana. Hobbes viveu cerca de 90 anos. Neste tempo, a Inglaterra passou por violentas transformações, 
que marcaram não só seus contemporâneos, mas a Idade Moderna europeia. Até hoje, a Revolução Inglesa é colocada na historiografia como precursora da Revolução Francesa e para tudo o que essa significa, em termos de mudanças e continuidades. O pensador não só leu a respeito da história Inglesa, mas como um expectador que também deseja ser interventor, refletiu sobre o que passou, dando sentido ao que viveu.

Hobbes insere-se numa concepção de história que se fez presente até o século XVIII, na qual os eventos eram compreendidos dentro de uma uniformidade potencial, passíveis de repetição, tornando-se, deste modo, veículos de interpretação do próprio futuro (KOSELLECK 2006, p. 54). As noções de tempo eram vindas de dois fenômenos observados: o movimento das estrelas e a sequência de governantes e dinastias.

Desta forma, assim como as estações se repetiam, as formas de governo, limitadas por natureza, ${ }^{8}$ se sucedem e se repetem, dentro de um ciclo. Assim, o sentido de revolução, no século XVII, remetia a conceitos da astronomia e física, se referindo tanto aos ciclos das gerações (geração, corrupção e morte) como as formas de governo que não se transformam, mas se alternam em repetições e ciclos. Ou seja, embora Hobbes esteja, em seus textos, analisando as leis civis, seus termos remetem à physis e a leis naturais ${ }^{9}$ (OSTRENSKY 2006, p. 26-29). As incursões do pensador pela história remetem a esse caráter de exemplo, de mostra da natureza humana que transparece principalmente nos momentos de guerra civil.

Nessa linha, a história tinha como objetivo mostrar o ciclo histórico e as melhores formas de evitá-lo, demonstrando o que ocorria caso o homem se revoltasse contra o poder soberano. O medo da morte é o que mantém os habitantes da cidade obedientes, já que se não houver um poder centralizador toda a estrutura é deteriorada.

Percebendo a importância da narrativa historiográfica, o filósofo, no decorrer de sua vida, fará incursões pela história. Para ele, ela seria importante na medida em que mostrava os acontecimentos, os erros passados e nos ensinava sobre a melhor forma de não repeti-los. Sem reflexões sobre as possibilidades de representar o passado, o pensador acreditava que pelo elencar dos fatos seria possível alcançar a sabedoria política.

Seu primeiro contato com a disciplina ocorreu através da tradução da Guerra do Peloponeso, de Tucídides. A tradução, entre as obras humanistas, merece destaque, já que ela ocorre do próprio grego, enquanto a prática muitas vezes

\footnotetext{
${ }^{8}$ Segundo a doutrina antiga, de origem aristotélica, havia um número limitado de formas constitucionais, que substituíam alternamente umas às outras, mas que não poderiam ser ultrapassadas. Aristóteles reconhece três tipos de Estado ou organização da pólis: monarquia, aristocracia e democracia. As transformações, nesse sentido, não são completas, já que retomam uma forma que de governo que já é antecipadamente conhecida. 9 "Na Inglaterra do século XVII, o conceito de revolução remete quase sempre a dois sentidos distintos, invariavelmente relacionados à astronomia e ao que hoje intitulamos física. O primeiro sentido é sinônimo de circunvolução e designa o processo cíclico de geração, corrupção e morte pelo qual passam todos os seres, mesmo os grandes corpos das repúblicas [...]. E, se genericamente a mutação própria da physis encontra similitude na instabilidade política, descendo aos particulares, a trajetória das esferas celestes, conforme a linguagem ptolomaica, ajuda a refletir sobre as condições pelas quais uma forma de governo muta-se noutra e sobre a trajetória dos regimes [...]" (OSTRENSKY 2006, p. 26).
} 
era de fazer a tradução de outra já existente. ${ }^{10} \mathrm{~A}$ obra é oferecida ao filho de seu ex- aluno (recém-falecido), então com dez anos. Consagrando o livro à memória do pai do menino, o segundo conde de Cavendish, ele fez uma dedicatória ao terceiro conde, uma pequena nota intitulada To the Readers (Para o leitor) e ao final um breve texto intitulado On the Life and history of Thucydide (Vida e história de Tucídides). O momento da publicação, não poderia ser mais propício, pois foi o ano em que o Parlamento entregou a Carlos I a Petição de Direitos (1628), na primeira demonstração dos conflitos que então prosseguiriam entre o rei e o Parlamento.

Para Hobbes era necessário traduzir do original a obra do historiador grego, já que ela encontrava-se deturpada em língua inglesa. Segundo coloca Skinner (1999, p. 317), o filósofo foi realmente exitoso em seu trabalho, sendo a obra posteriormente reeditada em 1634 e em 1648. A tradução valia o grande trabalho necessário devido aos ensinamentos advindos da obra do historiador grego.

Para Hobbes, a figura de Tucídides traria os ecos amplificados da Areté (excelência) de Péricles (estadista e orador ateniense), tanto na excelência da escrita como narrativa de acontecimentos, na manifestação dos próprios fatos e não em conjunturas próprias. A narrativa apresentada por Tucídides seria, portanto, a revelação de si mesma, sem digressões do historiador (PIRES 2007, p. 75). O historiador grego não teria se preocupado com as intenções, segredos e intimidades dos personagens, atendo-se à verdade, ou seja, às causas do evento narrado e seu desenvolvimento. Esta seria, segundo Hobbes, a tarefa da

20 história: mostrar as causas dos acontecimentos e não suas múltiplas formas de apreensão na mente dos que viveram os acontecimentos.

A tradução tinha como objetivo o ensino, o aprendizado através da história. O passado e o presente se relacionavam no entendimento da natureza humana, pois embora a história trate do particular e do momento, ela está relacionada ao universal, já que dispõe de elementos com os quais se pode estudar a natureza humana. Somente estudando o estado de guerra teríamos conhecimento sobre o caos presente no estado de natureza, demonstrando, assim, a necessidade constante de evitá-lo. Desta forma, o ser humano poderia compreender mais facilmente a necessidade de respeitar o poder soberano para a manutenção da paz.

\section{História como mestra da vida}

A história como mestra da vida carrega em si a concepção de certa imutabilidade do humano. Se o pretérito pode nos ensinar é porque existe entre

\footnotetext{
${ }^{10}$ Foi de Lorenzo Valla a primeira tradução de Tucídides para o latim entre 1448 e 1452 por encomenda do papa Nicolau V. O italiano seria um dos maiores filólogos e historiadores do humanismo, sendo nomeado historiador oficial de Afonso Aragão, encarregado de escrever a história do pai de Afonso. Seria esta a primeira aplicação da teoria historiográfica tucidideana, graças à importante página teórica sobre o valor da historiografia na ótica clássico-humanista (ALBANESE 2009, p. 296). Do trabalho de Valla foi feita uma tradução para o francês por Claude de Seyssel nas primeiras décadas do século XVI, dedicada a Luís XII, de quem era conselheiro régio. Da versão francesa surgiram duas outras, primeiro em inglês por Thomas Nicholl, em 1550, ofertada a Sir John Checke, tutor de Eduardo VI e outra na corte imperial de Carlos V, em 1564, para o espanhol Diego Gracián de Alderete, secretário real. Em 1545, Francesco de Soldo Strazzi traduziu Tucídides para o italiano oferecendo-a a Cósimo de Médici (PIRES 2007, p. 16).
} 
nós e os atenienses presentes na narrativa de Tucídides, por exemplo, um eixo comum, algo que nos identifica, que alguns chamam de "natureza humana". Além disso, as transformações, se existem, são lentas e o passado permanece, nessa lógica, válido. Para Thomas Hobbes isso é claro, já que as paixões que movem o homem estão presentes ao longo da história. São elas que promovem a guerra civil e, embora controladas pela vida social, permanecem somente adormecidas, encobertas pelo contrato, mas passíveis de controlar o homem caso a espada e a lei não o impeçam.

Se a história ensina e serve como "norte" para a prática política e para a formação do indivíduo, de forma alguma ela se restringe a mera repetição dos fatos narrados, pelo contrário, seguindo esta ótica, o historiador deve expressar seu julgamento sobre os fatos e sobre o que deve ou não ser relembrado. Quando Cícero fala das "leis da história", pela fala de Antônio (início do artigo), marca a diferença entre a eloquência praticada e desenvolvida em Roma e a cultivada pelos historiadores gregos.

Assim, é colocado, como ponto fundamental para a história, "não dizer algo falso", logo após afirma que a história não "deve dizer o que não é verdadeiro" e que "não haja, ao escrever, qualquer suspeita de complacência [...] nem o menor rancor" (Cícero, Do Orador, II). Ela devia ser neutra, verdadeira, sem partidos ou inclinações, devia narrar "a verdade", sem fingimento e sem complacências. Para Cícero, que entendia a história como parte constituinte da eloquência, ela era parte das funções do orador, embora "em si" ela nada signifique, já que precisa daquele que narra a história para fazê-la "brilhar" e tornar conhecido não só os personagens da história, mas seus escritores também.

[...] mas a própria construção repousa nos fatos e nas palavras: a inteligência dos fatos requer a ordem dos tempos e da descrição dos lugares. Pede também, já que em fatos importantes e dignos de memória e espera que haja primeiras deliberações, depois execução e em seguida resultados, que sobre as deliberações seja indicada qual é aquela que o autor aprova; sobre os feitos, que se declare não só o que se fez ou se disse, mas também de que modo; e, quando se fala que se devem ao acaso, à sabedoria ou à temeridade - e não se fale só dos feitos dos próprios homens, mas, com relações aos que se distinguem pela reputação e pelo nome, também da vida e do caráter de cada um [...] (Cícero, Do Orador, II, grifos meus].

Para Cícero, a história, tal como um trabalho de artesanato, exige do escritor o cuidado no tecer, na relação entre as palavras e os sentidos em que são colocados. Ou seja, tão importantes quanto os fatos são as formas do relato, a linha em que o narrador seguirá em seus textos. O que será apresentado passa pela escolha (deliberação), narração (execução) e persuasão (resultado). A história como pedagogia deve guiar-se pelo caminho das virtudes, escolhendo contar os atos memoráveis dos homens que eram dignos de tal menção.

Cícero foi inspiração para Hobbes para que ele estabelecesse sua própria visão sobre a história. Em tradução de Tácito, por exemplo, ele afirma que o historiador devia se deter, para relatar, no que não havia sido suficientemente 
narrado por outros. Escrevendo o que é relevante, os historiadores deveriam buscar a verdade, sem adulação ou intenção de agradar, conforme versa a "lei da história": "[...] a conhecida lei da história que diz que não se deve dizer nada de falso nem ocultar nada de verdadeiro [...]" (HOBBES Sobre o começo dos Anais, p. 47). De acordo com Tácito, as histórias anteriormente escritas eram falseadas pelo medo, já que os escritores estavam no poder. Desta forma, era plenamente justificável que o historiador romano se detivesse na narrativa.

Na linha de Cícero, o que devia servir de material para a historiografia não era o comum, o corriqueiro, mas o extraordinário, o que era grande "em si". Só a natureza é imortal, nossos atos são tão transitórios e efêmeros quanto nossa existência. A humanidade, enquanto parte do mundo natural, é eterna sendo, assim, incluída na categoria do ser-para-sempre - no entanto, as ações individuais são contaminadas, se não narradas, pelo mal da mortalidade juvenil. Se não lembrados, os atos heroicos são rapidamente esquecidos.

O tema da história não seria o comum, o "mortal", mas o extraordinário, o que, por sua monumentalidade, era digno de menção (ARENDT 2000, p. 72). Enquanto o movimento histórico estaria ligado à vida biológica, com início, meio e fim, a história, enquanto narrativa, devia ater-se ao que era grande "por si" e faria recordar o que já era glorioso. A tarefa do historiador seria, portanto, fazer lembrar os feitos memoráveis de homens virtuosos que deviam servir de exemplo às gerações posteriores.

Tucídides afirma que escrevera a história da guerra pela sua grandeza e 22 porque "esse foi o maior movimento conhecido na História, não apenas nos helenos, mas grande parte do mundo bárbaro [...] e praticamente da humanidade" (Tucídides A Guerra do Peloponeso, VII). De acordo com Hannah Arendt (2000, p. 78), a preocupação com a grandeza está relacionada à ligação entre a natureza e a história, sendo a imortalidade o denominador comum entre ambos.

[...] Imortalidade é o que a natureza possui sem esforço e sem assistência de ninguém, e imortalidade é, pois, o que os mortais precisam tentar alcançar se desejam sobreviver ao mundo em que nasceram [...]. A conexão entre história e natureza, pois, de maneira nenhuma é uma oposição. A história acolhe em sua memória aqueles mortais que, através de feitos e palavras, se provaram dignos de natureza, e sua fama eterna significa que eles, em pese sua mortalidade, podem comparecer na companhia de coisas que duram para sempre (ARENDT 2000, p. 78, grifos meus).

De acordo com Fernando Catroga (2000), a própria etimologia da palavra "histor", sugere a relação entre a história, o juízo, o testemunho e a visão. Se as narrativas homéricas convenciam pela descrição do inimaginável, do sublime, do espanto, a narrativa histórica devia persuadir pelos juízos argumentativos que deveriam zelar pela verdade. Assim como o aedo, inspirado pela Musa, cantava igualmente a gesta dos aqueus e dos troianos, o historiador se sentirá, desde o início, impelido a guardar a memória dos gregos e bárbaros. ${ }^{11}$

\footnotetext{
${ }_{11}$ De acordo com Afonso Gómez-Lobo, Tucídides traria em seu texto uma visão da história como justiça, já que na narração da última batalha da Guerra do Peloponeso é feito referência ao que os atenienses fizeram à ilha de Melos. Tucídides teria, dessa forma, mostrado o porquê do mal ocorrido à cidade grega (GÓMEZ-LOBO 1990, p. 265).
} 
Pensadores como Hobbes não foram historiadores de ofício, mas a tinham como importante no estudo e compreensão da sociedade e, no caso de Hobbes, da ciência civil. Sem grandes reflexões sobre teoria historiográfica ou metodologia, a percebiam como veículo de ensino sobre a natureza humana e sobre os melhores caminhos diante do futuro incerto. Leitor de historiadores clássicos, procurou aprender sobre sua forma de narrativa. Percebemos o que a história significa para o pensador por deduções, reflexões sobre seu método e sua própria filosofia. Perceber os limites e possibilidades historiográficas de um autor que não se via necessariamente como historiador nos possibilita refletir e entender melhor a própria modernidade e sua concepção sobre o passado, o presente e o próprio futuro.

\section{Referências bibliográficas}

AHRENSDORF, Peter J. The Fear of Death and the Longing for Immortality: Hobbes and Thucydides on Human Nature and the Problem of Anarchy. American Political Science Review, v. 94, n. 3, p. 579-593, 2000.

ALBANESE, Gabriella. A Redescoberta dos historiadores antigos no Humanismo e o nascimento da historiografia moderna. In: MURARI PIRES, Francisco (Org.). Antigos e Modernos: diálogos sobre a (escrita da) história. São Paulo: Alameda, 2009, p. 19-70.

ARENDT, Hannah. Entre o passado e o futuro. Tradução de Mauro W. Barbosa de Almeida. São Paulo: Perspectiva, 2000.

ARISTÓTEleS. Poética, Organon, Política, Constituição de Atenas. São Paulo: Nova Cultural, 2000.

CATROGA, Fernando. Ainda será a História a Mestra da Vida? Revista de Estudos Ibero-Americanos, v. 32, 7-34, 2006.

CÍCERO. A origem da História, as leis da história e a eloqüência do fórum. In: HARTOG, François. A história de Homero a Santo Agostinho. Tradução de Jacynto Lins Brandão. Belo Horizonte: Ed. UFMG, 2001, p. 145-151.

Do orador. In: HARTOG, François. A história de Homero a Santo Agostinho. Tradução de Jacynto Lins Brandão. Belo Horizonte: Ed. UFMG, 2001, p. 144-145.

COLODRERO, Andrés Jiménez. Estudio preliminar. In: HOBBES, Thomas.

Discursos Histórico-Políticos. Buenos Aires: Corla, 2006, p. 7-39.

GOMEZ-LOBO, Afonso. El Dialogo de Melo y la vision Histórica de Tucídides.

Estudos Públicos, n. 44, p. 247-273, 1991.

CROOKE, William. To the Booksseller to the reader. In: HOBBES, Thomas.

Behemoth: the history of the causes of the civil wars and artifices by wich. Oxford: Oxford Univesity, 1966, p. 160-170. 
GREENE, David. Introduction. In: THUCYDIDES. The Peloponnesian War. Traducing of Thomas Hobbes. Chicago: The University of Chicago Press, 1989, p. vii-xiii.

HARTOG, François. O Espelho de Heródoto: Ensaio sobre a representação do outro. Tradução de Jacyntho Lins Brandão. Belo Horizonte: Ed. UFMG, 1999.

A história de Homero a Santo Agostinho. Tradução de Jacynto Lins Brandão. Belo Horizonte: Ed. UFMG, 2001.

Os Antigos, o passado e o presente. Tradução de Sorria Lacerda, Marcos Veneu e José Otávio Guimarães. Brasília: Ed. UnB, 2003.

HOBBES, Thomas. Behemoth ou o Longo Parlamento. Tradução de Eunice Ostrensky. Belo Horizonte: Ed. UFMG, 2001.

Behemoth; or the Long Parliament. Edição de Ferdinand Tönnies. Chicago: University of Chicago Press, 1990.

Leviatã ou Matéria, forma e poder de um estado eclesiástico e civil. Tradução de João Paulo Monteiro e Maria Beatriz Nizza da Silva. São Paulo: Nova Cultural, 1999.

- Vida de Thomas Hobbes de Malmesbury escrita em verso por el autor. In: RODILLA, Miguel Ángel (Org.). Vida de Thomas Hobbes de Malmesbury escrita en verso por el autor. Madrid: Editoral Tecnos S. A., 1992, p. 7-12.

. Sobre el comienzo de los Anales, de Tácito. In: HOBBES, Thomas.

Discursos Histórico-Políticos. Buenos Aires, Corla, 2006, p. 39-77.

Sobre las leyes. In: Discursos Histórico-Políticos. Buenos Aires: Corla, 2006, p. 105-117.

LA CAPRA, Dominick. Historia Intelectual: repensar La historia intelectual y leer textos. IN: PALTI, Elias José. "Giro Linguístico" e historia intelectual. Buenos Aires: Universidade Nacional de Quilmes, 1998, p. 105-117.

KOSELLECK, Reinhard. Futuro Passado. Tradução de Wilma Patricia Mass e Carlos Almeida Ferreira. Rio de Janeiro: Contraponto, 2006.

LATOUR, Bruno. Jamais fomos modernos: Ensaio de antropologia simétrica. Rio de Janeiro: Ed. 34, 1994.

OSTRENSKY, Eunice. Advertência ao leitor. In: HOBBES, Thomas. Behemoth ou o Longo Parlamento. Tradução de Eunice Ostrensky. Belo Horizonte: Ed. UFMG, 2001, p. 5-6.

Revoluções no Poder. São Paulo: Alameda, 2006.

PIRES, Francisco Murari. Modernidades Tucideanas. São Paulo: Edusp, 2007. SKINNER, Quentin. As fundações do pensamento político moderno. Tradução de Renato Janine Ribeiro e Laura Teixeira Mota. São Paulo: Companhia das letras, 1996. 
. Razão e Retórica na Filosofia de Thomas Hobbes. Tradução de Vera Ribeiro. São Paulo: Ed. Unesp, 1999.

TONNIES, Fernando. Thomas Hobbes. Madrid: Revista de Ocidente, 1932 . Prefácio. In: HOBBES, Thomas. Behemoth ou o Longo Parlamento. Tradução de Eunice Ostrensky. Belo Horizonte: 2001, p. 25-29.

TUCIDIDES. História da Guerra do Peloponeso. Tradução de Mário Gama Cury. Brasília: Ed. UnB, 2001.

VOGT, Débora Regina. A história como laboratório comprobatório: a luta entre o Behemoth e o Leviatã em Thomas Hobbes. História e-História, v. 1, n. $1,2009$. 